\title{
Urban Green Land Ecological Suitability Assessment Based on GIS in Arid Areas: Beitun City, Xinjiang, as an Example
}

\author{
Wenli Wu' ${ }^{1}$, Ye Yuan' ${ }^{1}$ Chunbo Huang ${ }^{2}$, Wei Dong ${ }^{1}$, Zongchi Fu ${ }^{1 *}$ \\ ${ }^{1}$ Agriculture College, Shihezi University, Shihezi, Xinjiang 832000, China \\ ${ }^{2}$ School of Geography and Information Engineering, China University of Geosciences, Wu Han, Hubei 430074, China
}

Received: 15 January 2021

Accepted: 3 May 2021

\begin{abstract}
Arid areas are faced with frequent droughts and sandstorms, and through variations of the harsh natural conditions. Urban green space is an important ecological infrastructure to improve the harsh climate, but green space system planning often exposes strong subjectivity. The suitability evaluation of urban green space can be based on the powerful spatial analysis capabilities of GIS, through investigation and comprehensive analysis of the suitability of the land for various uses, the level of quality and its restriction status, etc., so as to classify and grade the ecological functions of urban green space. Taking Beitun city in Xinjiang Province as an example, according to local conditions, evaluation factors were selected from five aspects: wetland resources, flora and fauna habitat, landscape features, anthropogenic disturbance and temperature risk; the factor weights were determined by analytic hierarchy process; a green space suitability evaluation system based on three levels of "target-criterionindex" was established, and on this basis. Using the GIS spatial overlay analysis module, five levels of urban green space ecological suitability zones were delineated: the most suitable green area (23.6\%); the high-suitability area (32.1\%); the mid-suitability area (21.6\%); the low-suitability area (14.5\%); and the unsuitable area $(8.2 \%)$, Combined with the current situation of land use and the demand of urban development in Beitun city, the functional zoning of urban green space ecological facilities are divided into a green ecological restoration area, a green ecological conservation area, low-and medium-impact development areas and a green suitable development area; on a scientific basis, allocation of green space resources and protection countermeasures are proposed to construct green space in each area as part of the theoretical guidance for Beitun. The results show that appropriate indicators and methods can more accurately reflect the actual and demand of urban green space development in arid areas, and play a practical guiding role. The research provides a useful attempt and supplement for the practice and application of the method of division of green space ecological suitability in arid cities.
\end{abstract}

Keywords: arid area, suitability evaluation, green land, AHP, GIS

*e-mail: fzc_agr@shzu.edu.cn 


\section{Introduction}

Under the influence of the subjective experience of planners, green space planning often damages the public interest because of unscientific leading factors. Whether prior to urban planning or through green space ecological facilities based on urban planning, it is necessary to rationally evaluate current ecological resources and guide the planning and construction of green space through the evaluation of green space suitability [1-2]. It is necessary to carry out elastic planning of key ecological infrastructure based on behavior of urban lifelines for long-term planning. How to mitigate and adapt to the negative impacts of adverse climate change, and how to implement effective and feasible strategies for various scenarios, these problems are attracting more and more people's attention [3].

Suitability analysis refers to the analysis of land for a specific development activity, and the regional division of an appropriate grade is proposed through the comprehensive consideration and evaluation analysis of multiple influencing factors [4-5]. With the emphasis on systematization and scientificity in urban land planning, the organic combination of multiple disciplines shows a broad development prospect [6-7]. Using the Water Evaluation And Planning System (WEAP) and MATLAB can help us to try and select the best measures to mitigate Water stress at the watershed level [8]. Using the Geographically Weighted Regression(GWR) and landscape index can help us to explore and optimize the spatial pattern of ecological green space in urban and rural areas [9] The method of ecosystem quality assessment using the Geographic Information System (GIS) an help us to alleviate the contradiction of water use in arid inland river basins [10].

Applying suitability analysis to the urban green space planning process, by evaluating the factors that affect the ecological environment, we can find the areas that most need to build green space, which can provide a scientific reference for optimizing the layout of urban green space.

Compared with the general area of China, the northwest arid areas are faced with frequent droughts and sandstorms, and through variations of the harsh natural conditions [11-13], and cities and towns in harsh environments more urgently need the construction of urban green space systems with the reasonable layout and suitable size [15-16]. However, the initial construction of the urban green space system and the blind copying of foreign and mainland urban greening patterns, has strong subjectivity and hysteresis as with the status quo [12]. The issue of how to effectively reduce the construction costs of urban green space systems and the consumption of resources and energy of green space construction is an urgent problem for green vegetation and landscape ecological construction in ecological towns in arid areas of Northwest China. This paper highlights the necessity of evaluating the suitability of urban green space in arid area, focusing on the representative city of Xinjiang-Beitun city. The paper also uses the spatial analysis ability of GIS to find the problems faced by the urban green space ecology in arid area, and uses the analytic hierarchy process to select scientific and reasonable quantitative indexes, and discusses that the suitability evaluation can be used as the basic work in the early stage of urban green space system planning.

Based on the theory of ecology, suitability evaluation to guide the planning of green space, to coordinate the relationship between urban development and ecological protection, to establish the suitability analysis criteria by using the logical rules of ecological factors, and to distinguish the functional zoning of ecological suitability of green space are the hot spots and frontiers of the research on the implementation of urban sustainable development strategy. However, the previous research results mostly focused on the evaluation of land use, and there were few studies on the suitability evaluation of green space planning, and the lack of evaluation duality and systematic consideration often faced with difficulties, which affected the accuracy of evaluation results to a certain extent. Compared with them, this paper pays more attention to the pertinence and systematism of the evaluation indexes, so as to reveal the main reasons affecting the urban green space ecosystem in typical arid areas, provide scientific basis for urban green space planning according to local conditions, and also provide reference for the planning and evaluation of urban green space in other arid areas.

The paper is divided into the sections: 1) Introduction. The necessity of green space suitability evaluation in arid cities was expounded. 2) Material and Methods. The general situation of the research area and the process of suitability evaluation system construction are mainly introduced. 3) Results and Discussion. The results were analyzed and discussed from the land use type map, the superposition map of each index factor and the classification map of green space suitability. 4) Conclusions. The applicability of the evaluation index system for the suitability of urban green space in arid area was summarized .

\section{Methods and Materials}

\section{Study Area}

Beitun city is located between Altay city and Fuhai County in the north of the Xinjiang Uygur Autonomous Region. Derenshan, to the east of the urban area, is a platform formed by tertiary mudstone surfacing in the urban area of Beitun, with an area of $8.5 \mathrm{~km}^{2}$ and a relative height difference of $50 \mathrm{~m}$ from the built-up area of Beitun. Beitun city extends along the Ertysh River for $10 \mathrm{~km}$ from east to west, with an average width of $1 \mathrm{~km}$ from north to south. The study area (Fig. 1) is located on the south bank of the Irtysh River, with 


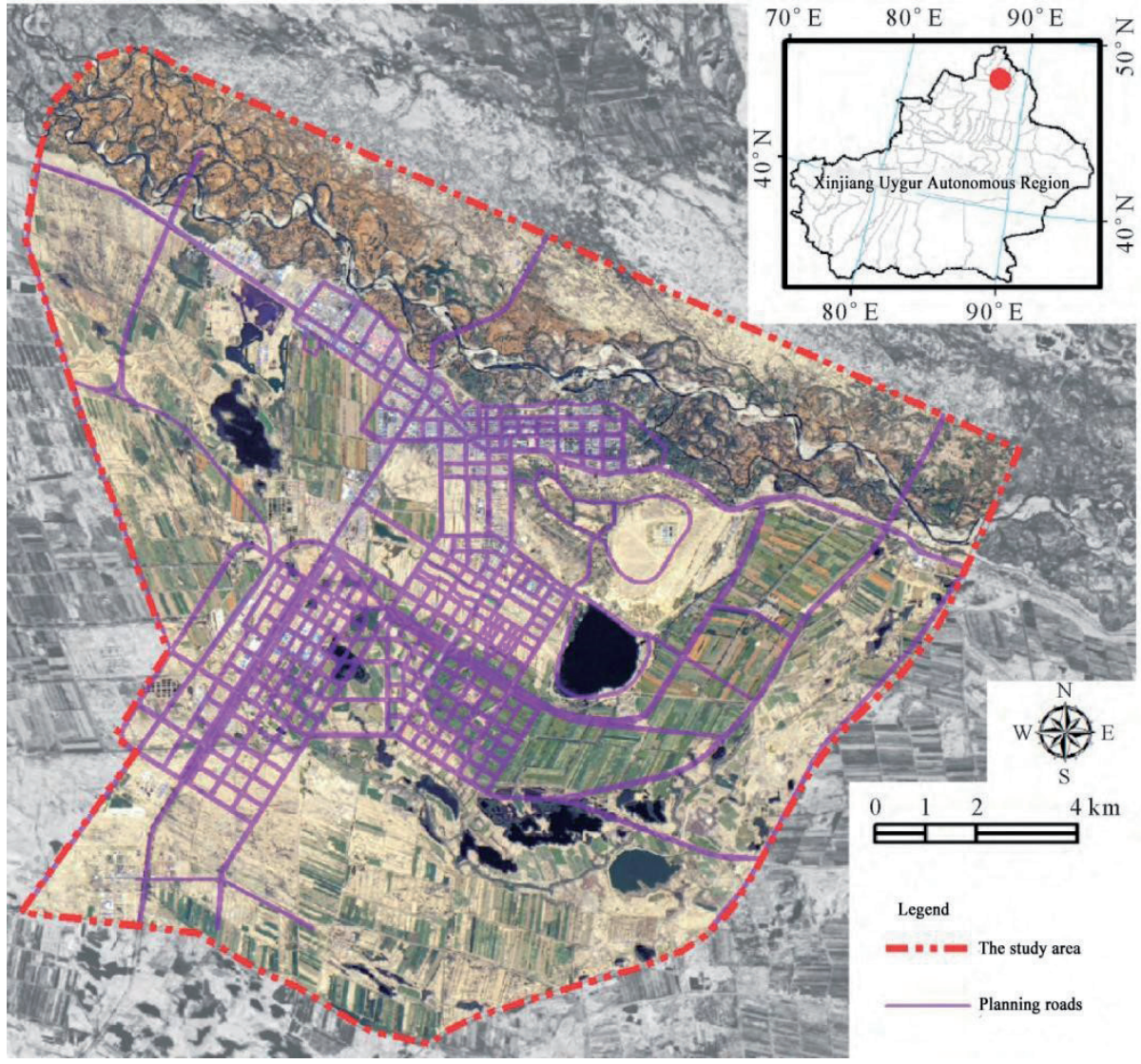

Fig. 1. The location of the study area.

a total area of $237.4 \mathrm{~km}^{2}$. The rugged and colorful hillside in the study area is a unique geological landscape. The terrain on the top of Deren Mountain is flat, and most areas in the east and south still maintain the original desert and Gobi landform, with a small amount of sandy vegetation [17-18]. To the southeast of the study area is Nanhu Lake, with a water surface of approximately $2.1 \mathrm{~km}^{2}$ and a lake surface elevation of approximately $521.4 \mathrm{~m}$. By the end of 2009, the urban population was 53,000 , the built-up area was $12.23 \mathrm{~km}^{2}$, and the construction land per capita was $230.9 \mathrm{~m}^{2}$.

Beitun is located in the central hinterland of Eurasia, belonging to the middle temperate continental climate zone, has typical arid climate characteristics: a dry climate, low levels of precipitation, and a large evaporation. The annual average temperature is $4.1^{\circ} \mathrm{C}$, extreme maximum temperature of 41.5 degrees Celsius, extreme minimum temperature of -49 degrees Celsius, the annual precipitation is $93.9 \mathrm{~mm}$, and the annual evaporation is $1661.4 \mathrm{~mm}$. The frost free period of the entire year is 140-154 d. As a result of repeated river scouring, the deserts on both sides of the river have been transformed and gradually formed into alluvial plains. The main types of natural soil are dark meadow soil, ordinary meadow soil, salinized meadow soil, irrigated meadow soil, wet beach soil, meadow brown calcium soil and semi fixed aeolian sand soil. Affected by climatic conditions, the plain vegetation is sparse, and the vegetation coverage is $30 \%-40 \%$. As the Irtysh River Valley covers a vast area, the natural conditions are complex, and the vegetation types are rich and diverse, forming a mixed structure of Joe, irrigation and grass. Under the influence of river valley moisture conditions, stands are distributed on both sides of the river valleys and channels. Due to low groundwater levels and sparse vegetation, desert shrubs dominate the piedmont gravel zone.

\section{Data Source}

The data sources mainly include Landsat 8 images from the 2014 growing season and nongrowing season, digital elevation model data obtained by Aster, a 1:10000 topographic map of Beitun city, the urban master plan of Beitun city 2010-2030, the statistical yearbook of Beitun city and other statistical data.

First, based on the interpretation of remote sensing images of Beitun, water bodies, urban construction land, forestland, farmland, roads, industrial pollution areas, bare land, etc. [19] were identified for a total of 7 kinds of land use/cover types, the present situation of the agricultural land use and ecological resource distribution in Beitun was analyzed, and then, based on the characteristics of the urban green space planning in arid areas, important factors influencing the green space layout of Beitun agricultural city were identified. 
Buffer analysis and landscape type recognition were used to obtain the shadow horizontal spatial distribution characteristics of ring green space layout factor; the DEM and topographic maps were used to obtain the vertical spatial distribution features of slope and elevation in the study area. Taking Landsat remote sensing thermal infrared band images in the growing season as the data source, a surface temperature spatial distribution map of Beitun city was obtained through the inversion research method of relatively bright and mild surface temperatures.

\section{Suitability Evaluation System and Technical Process}

According to the formation mechanism of major ecological environmental problems [20-21], the ecological suitability evaluation of urban green space should analyze the regional distribution law of ecological environmental suitability and define the possible range and degree of specific ecological environmental problems (Fig. 2a). Green space is an open and semiclosed system, located in the transition zone between human activities and natural landscapes [22], while the ecological environment in arid areas is particularly appropriate to affect the normal development and location of green space as well as the current status of green space. Based on the land use status and the characteristics and actual situation of the regional green space in Beitun city, the green space suitability evaluation system was constructed from five aspects: wetland resources, animal and plant habitat, landscape characteristics, human disturbance and temperature risk (Fig. 2b). Suitability grades are usually given in the 5 levels of very appropriate, more appropriate, low in suitability, appropriate and

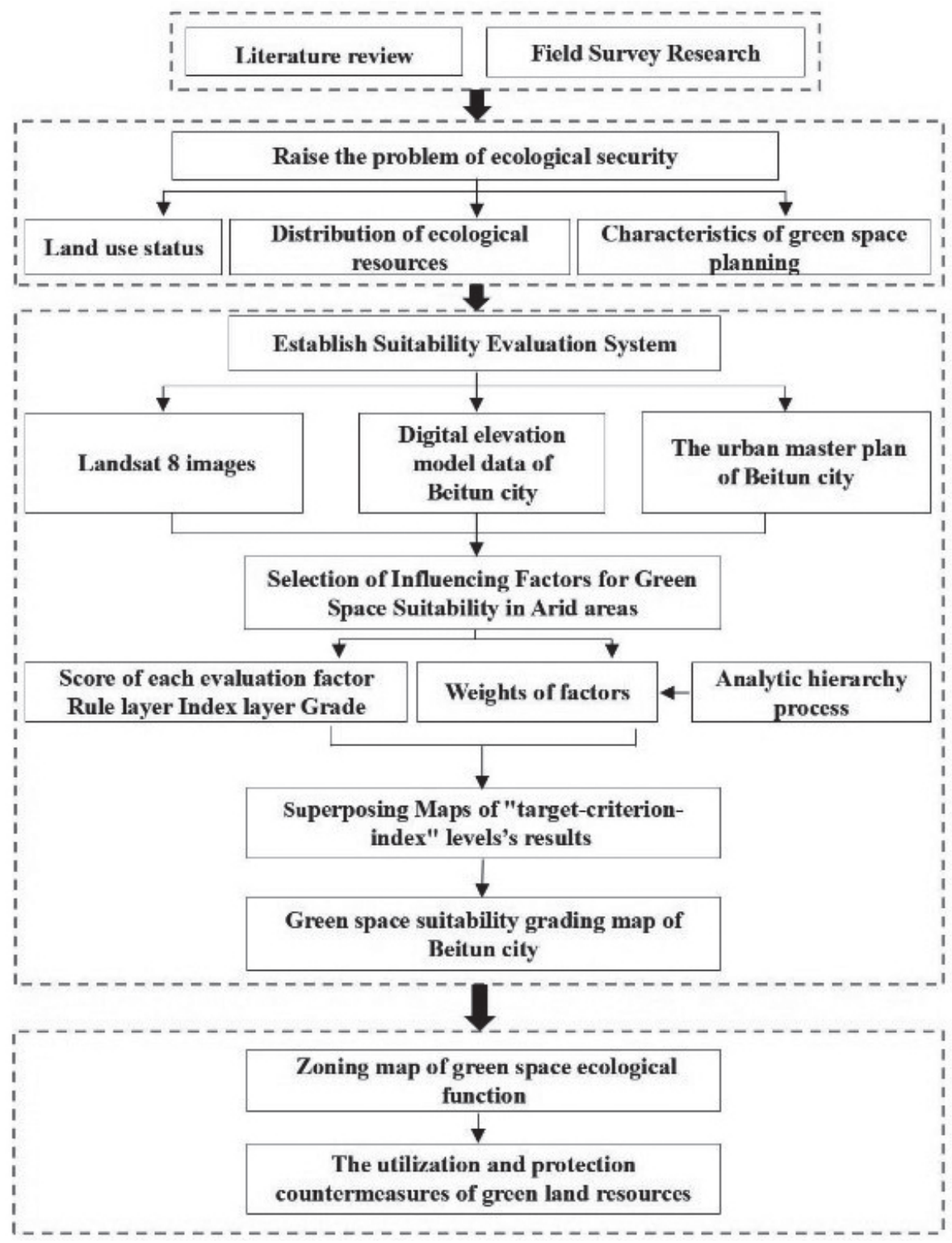

Fig. 2a). The research methodology. 


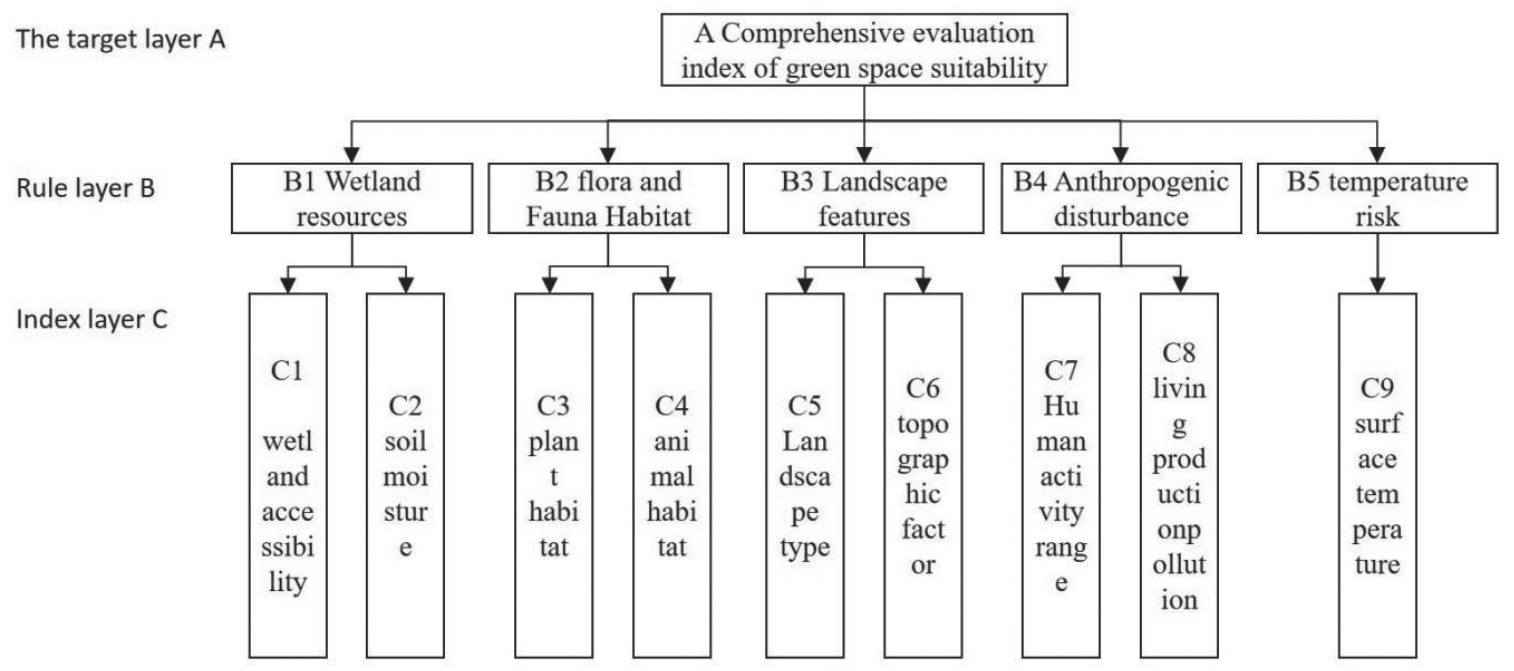

Fig. 2b). Green space suitability evaluation system in Beitun city.

inappropriate. Using the strong spatial analysis ability of GIS to influence the composition of urban green space ecological environment factors according to certain weighted superposition simulation [23], the regional ecological environment suitability spatial distribution and integrated suitability zoning are an objective analysis of the problems of urban ecology based on the most direct and effective method. The basic expression of the green space suitability model is as follows:

$$
\mathrm{S}=\sum_{i=1}^{n} W_{i} \times x_{i}
$$

In the formula, $\mathrm{S}$ is the ecological suitability; $\mathrm{W}_{\mathrm{i}}$ is the weight of the ith suitability factor $(I=1,2,3 \ldots, n)$; and $\mathrm{x}_{\mathrm{i}}$ is the suitability score of the ith factor. The factors determined the scores of different types/standards according to the evaluation target and assigned a score of $\{9,7,5,3,1\}$. The larger the score is, the better the ecological environment of green space, and the higher the suitability. +

\section{Selection of Influencing Factors for Green Space Suitability in Arid Areas}

\section{Wetland Accessibility}

As an important part of the ecosystem in arid regions, river systems are a key factor restricting the growth of green space [24]. According to the current situation of land use, buffer analysis is carried out for the existing wetland resources, and the adaptive level of green space is set according to the buffer distance.

\section{Soil Water Content}

The normalized differential water index (NDWI) can reflect surface water information [25] and be used to analyze the surface water distribution characteristics, area, water amount and calculation, which is of great significance for the development, protection and utilization of water resources. In addition, the index can supplement the difference and richness of different wetland resources.

\section{Plant Habitat}

The normalized difference vegetation index (NDVI) can reflect the vegetation coverage and plant habitat; the higher the NDVI vegetation status of the environment is, the better the level of green space adaptability and the higher the score.

\section{Animal Habitat}

Due to the special geographical and climatic conditions in Beitun, there are only relatively common birds and small animals in this area, while different landscape types provide different habitats and food for birds and small mammals. In this study, landscape types were used as indicators to reasonably evaluate the suitability of animal habitat types.

\section{Landscape Types}

Landscape differences limit the planning of green space ecological facilities, and the landscape type is the direct embodiment of the modification of the natural environment by humans [26], the combination of landscape types in reports and the interpretation results of land use classification levels in the landscape of Beitun agricultural city; in addition, the resulting environmental pollution tolerance level of urbanization judges the green land adaptability.

\section{Terrain Factors}

Topography controlled the planning and construction of green space facilities, and the elevation and slope of 
Beitun was analyzed using DEM data. The slope reflects the degree of the surface slope. If the slope is small, the terrain is relatively flat, and the urban construction cost is low. If the slope is too large, water retention is poor, which is not conducive to vegetation growth and easily causes soil erosion and geological disasters. The higher the elevation is, the more unsuitable the urban green space construction, but the lower the human intervention is, the more suitable the area is for biological habitats and the higher the suitability of urban green space is.

\section{Scope of Human Activities}

The disturbance of human activities is an important indicator affecting the construction of green space ecological facilities. The hard ground caused by rapid urbanization seriously reduces the ecological service functions of urban green spaces and limits the planning and construction of green space ecological foundations [27]. The road is the direct medium of human activities. The buffer zone of the road is analyzed to determine the suitability of green space according to the distance of human activities.

\section{Domestic Production Pollution}

Waste gas, wastewater and other pollutants cause great damage to plant growth and the ecological environment. Planning protection and isolation green space around pollution sources can effectively improve the ecological environment nearby.

\section{Temperature Risk}

Beitun is located in Xinjiang, which is affected by not only the urban heat island effect but also the temperature regulation of different landscapes. According to the difference of the instantaneous surface temperature in autumn [28], green space adaptability is divided into three grades: high (low surface temperature), medium (medium surface temperature) and low (high surface temperature).

\section{Classification of Suitability}

In combination with the current ecological environment and the actual situation of urban construction in Beitun city, each index was graded, and a green space suitability score was assigned (Table 1). NDWI, NDVI, altitude and surface temperature were all graded through the "natural discontinuous method" in ArcGIS software [29].

\section{Determination of Weights}

According to the importance degree of each criterion in terms of the ecological suitability, a comparative analysis is conducted according to the analytic hierarchy process [30], and a judgment matrix is constructed. The weight value of each quasi-measurement is calculated (Table 2). The largest eigenvalue of the $\lambda \max =5.21, \mathrm{CI}$ is the matrix deviation consistency index $(\lambda \max -n) /(n-1)=0.05, \mathrm{RI}$ is the mean random consistency index of the corresponding matrix of order $5 \mathrm{RI}=1.12$, and the mean random consistency index random consistency ratio is $\mathrm{CR}=\mathrm{CI} / \mathrm{RI}=0.0469<0.1$; based on the judgment matrix and the consistency check, the weight satisfies the requirements of the study. Through the expert consultation method, the index factors under the criterion layer are treated with equal weights.

Table 1. Score of each evaluation factor Rule layer Index layer Grade(score) Wetland resources.

\begin{tabular}{|c|c|c|}
\hline Rule layer & Index layer & Grade (score) \\
\hline \multirow{2}{*}{$\begin{array}{l}\text { The wetland } \\
\text { resources }\end{array}$} & Soil moisture content & $<100 \mathrm{~m}(9), 100 \sim 300 \mathrm{~m}(7), 300 \sim 500 \mathrm{~m}(5), 500 \sim 1000 \mathrm{~m} \mathrm{(3),}>1000 \mathrm{~m}(1)$ \\
\hline & Soil moisture content & $\begin{array}{l}\text { NDWI high (9), NDWI higher (7), NDWI middle (5), NDWI lower (3), } \\
\text { NDWI low (1) }\end{array}$ \\
\hline \multirow{2}{*}{$\begin{array}{c}\text { Animal and plant } \\
\text { habitat }\end{array}$} & Plant habitat & $\begin{array}{l}\text { NDVI high (9), NDVI higher (7), NDVI middle (5), NDVI lower (3), NDVI } \\
\text { low (1) }\end{array}$ \\
\hline & Animal habitat & Water body and forest land (9), far mland (5), Bare land (1), The habitat (0) \\
\hline \multirow{2}{*}{$\begin{array}{l}\text { Landscape } \\
\text { features }\end{array}$} & Landscape types & $\begin{array}{l}\text { Water body and forest land (9), far mland (7), Bare land (5), Land and roads for } \\
\text { urban construction (3), Industrial polluted area (1) }\end{array}$ \\
\hline & Terrain factors & $\begin{array}{l}\text { High at an altitude of (9), middle at an altitude of (5), low at an altitude of (1); } \\
\text { A steep slope }>15^{\circ}(9) \text {, Gentle slope } 5 \sim 15^{\circ}(5) \text {, The ground }<5^{\circ}(1)\end{array}$ \\
\hline \multirow{2}{*}{$\begin{array}{l}\text { Human } \\
\text { disturbance }\end{array}$} & Range of human activity & $>500 \mathrm{~m}(9), 300 \sim 500 \mathrm{~m}(7), 100 \sim 300 \mathrm{~m}(5), 50 \sim 100 \mathrm{~m}(3),<50 \mathrm{~m}(1)$ \\
\hline & Domestic production pollution & $>1000 \mathrm{~m}(9), 500 \sim 1000 \mathrm{~m}(7), 300 \sim 500 \mathrm{~m} \mathrm{(5),}, 150 \sim 300 \mathrm{~m} \mathrm{(3),}<150 \mathrm{~m} \mathrm{(1)}$ \\
\hline Temperature risk & The surface temperature & $\begin{array}{l}\text { The te mperature high (9), The te mperature middle (5), The te mperature low } \\
\text { (1) }\end{array}$ \\
\hline
\end{tabular}


Table 2. Weights of factors.

\begin{tabular}{|c|c|c|c|c|c|c|}
\hline Factor & $\begin{array}{c}\text { Wetland } \\
\text { resources }\end{array}$ & $\begin{array}{c}\text { Habitat } \\
\text { quality }\end{array}$ & $\begin{array}{c}\text { Landscape } \\
\text { features }\end{array}$ & $\begin{array}{c}\text { Human } \\
\text { disturbance }\end{array}$ & $\begin{array}{c}\text { Temperature } \\
\text { risk }\end{array}$ & $\begin{array}{c}\text { Weight } \\
\text { value }\end{array}$ \\
\hline Wetland resources & 1 & $1 / 3$ & $1 / 2$ & 1 & 2 & 0.149 \\
\hline Habitat quality & 3 & 1 & 3 & 2 & 3 & 0.397 \\
\hline Landscape features & 2 & $1 / 3$ & 1 & 2 & 3 & 0.202 \\
\hline Human disturbance & 1 & $1 / 2$ & $1 / 2$ & 1 & 1 & 0.177 \\
\hline Temperature risk & $1 / 2$ & $1 / 3$ & $1 / 2$ & $1 / 3$ & 0.075 \\
\hline
\end{tabular}

Table 3. Area of each land use/cover type in Beitun.

\begin{tabular}{|c|c|c|}
\hline Land use/cover types & Area/km & Proportion/\% \\
\hline Water & 12.63 & 5.32 \\
\hline Woodland & 100.64 & 42.39 \\
\hline Farmland & 71.97 & 30.32 \\
\hline Road & 4.65 & 1.96 \\
\hline Urban construction land & 10.37 & 4.37 \\
\hline Industrial polluted area & 0.68 & 0.28 \\
\hline Bare land & 36.46 & 15.36 \\
\hline
\end{tabular}

\section{Results and Discussion}

\section{Land Use Status Analysis}

Land use areas of various types in the study area are obtained by remote sensing interpretation (Table 3).
Woodland area is the largest, at approximately $100.64 \mathrm{~km}^{2}(42.39 \%)$. Farmland is next at $71.97 \mathrm{~km}^{2}$ (30.32\%). Artificial hard surface accounts for approximately $6.33 \%$ of the total area of the study area (among which the road area is $4.65 \mathrm{~km}^{2}$, and the urban construction land area is $10.37 \mathrm{~km}^{2}$ ), in addition to approximately $0.68 \mathrm{~km}^{2}(0.28 \%)$ of industrial pollution area. Although the study area is located in Xinjiang, forestland and farmland are the main landscapes in this area, water resources are abundant $(5.32 \%)$, and the ecological foundation is superior.

The spatial distribution map of land use/cover (Fig. 3) shows that forestland is distributed in the north of the study area and gradually decreases from the north to the south, while farmland is the main landscape in the south. Water is the most important natural limiting factor. The Irtysh River in the north can provide good growth conditions for forest growth, and the topography from the north to the south gradually improves. Artificial water diversion can guarantee

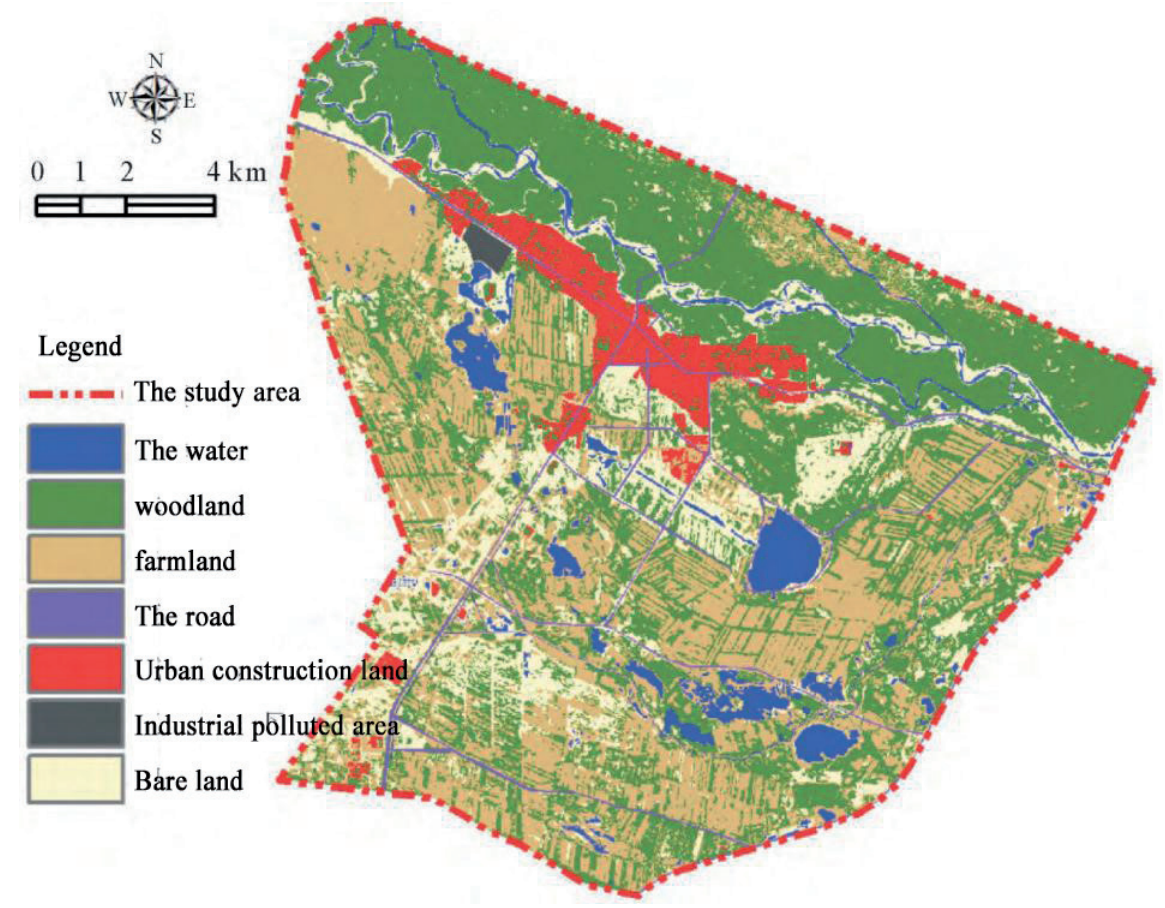

Fig. 3. The land use map of Beitun. 
the normal growth of crops, so the south is developed into farmland.

Water is the most precious resource in Xinjiang, and the water in the study area is evenly distributed. Rivers, Small West Lake and South Lake have become the main wetland landscape, and the channels among the patches of wetlands guarantee the connection of water resources. In addition, artificial canals enhance the exchange of information and the flow of materials in the patches of wetlands while solving the problem of farmland cultivation. The bare land in arid areas is more prone to conversion and is easily developed. The patches of bare land in Beitun city are broken and scattered, which provide land security for the restoration of green land. Beitun is an undeveloped city with a concentrated land distribution, few roads and a simple distribution. The industrial polluted area in the northeast is a body of water that has been seriously polluted.

\section{Suitability Analysis of Green Space}

Beitun city is close to the Erqihe River, and although there are water resources such as Nanhu Lake and Yudai Lake, this area is vulnerable to seasonal local water shortage. The accessibility of wetlands, as determined by the distance to a water body (Fig. 4, C1), shows that the accessibility of wetlands near rivers, lakes, canals and other wetland resources is extremely high, while the accessibility of wetlands in cities and towns is the lowest. The NDWI of water bodies is the highest (Fig. 4, C2), and the urban construction land and surrounding soil moisture content are relatively high. The suitability of wetland resources (Fig. 4, B1) is obtained by the superposition of equal weights. The most suitable area accounts for $18.8 \%$ of the total area and is mainly distributed around the wetland, which is suitable for green space development or ecological protection. The high-suitability area $(23.6 \%)$ has a great direct impact on wetland ecology and is suitable for green space construction. The mid-suitability area $(18.5 \%)$ is a transitional zone that has a good ecological environment but is vulnerable to damage. The lowsuitability area $(27.1 \%)$ is far away from the wetland landscape and has little direct impact; inappropriate areas $(12.0 \%)$ are mainly urban construction land, which is hard and difficult to use for large-scale green space construction.

Plant habitats based on the NDVI classification (Fig. 4, C3) show that water bodies such as lakes and the Irtysh River have a low VEGETATION coverage, while those surrounding water bodies have a high vegetation coverage and plant species richness. Animal habitats based on landscape types (Fig. 4, C4) show that natural resources such as water bodies and woodlands are most suitable for animal survival, while farmland provides food and activities for small mammals and birds. The habitat suitability of animals and plants was obtained by equal weight superposition (Fig. 4, B2). The most suitable area (46.2\%) was mainly forestland and some farmland, with a high biodiversity. The highsuitability area $(21.4 \%)$ was embedded in the areas with a concentrated vegetation distribution, providing space for biological expansion. The mid-suitability area $(11.7 \%)$ is a comprehensive transitional zone, which can be developed rationally in combination with the regional economy and ecological protection. The lowsuitability area $(14.2 \%)$ and the inappropriate area $(6.4 \%)$ are areas of human activities, inset with a small amount of vegetation, which is not enough to provide a good living environment for organisms. Therefore, the ecological environment of this area can be improved through the construction of forest networks.

The better the ecological environment and the more abundant the resources, the higher the green space suitability of the landscape type is (Fig. 4, C5). Topography restricts the construction of green space. The results of the topography analysis show that the elevation of Beitun changes substantially and has less sloping land. The comprehensive elevation and slope show that the suitability of the southeast is the highest, while that of the northwest is the lowest (Fig. 4, C6). The landscape feature suitability of the green space is obtained by equal weight superposition (Fig. 4, B3). The original landscape of the most suitable area $(28.9 \%)$ is better. The high-suitability area $(25.9 \%)$ is mainly distributed around the Irtysh River, which should be reasonably protected and regulated. In the mid-suitability area (25.8\%), the ecological construction of green space can be carried out. It is difficult to construct green space in low-suitability areas (13.6\%) and unsuitable areas (5.8\%).

The farthest area of activity was north of the Irtysh River and west of the study area, while the activity was strong near towns and farmland (Fig. 4, C7). Domestic and production pollution is distributed around the urban construction land, and the direct pollution 1000 $\mathrm{m}$ away from the construction land is less (Fig. 4, C8). Human disturbance is an important index affecting the construction of green space ecological facilities. Rapid urbanization makes the land hard, which leads to the decrease of green space ecological service functions and limits the planning and construction of green space ecological foundations. The weights of $\mathrm{C} 7$ and C8 are superimposed to obtain the intensity of human disturbance of the green space (Fig. 4, B4). The slight disturbance area accounts for $63.6 \%$ of the total area, which is suitable for planning and construction of green space or other ecological facilities.

The urban heat island effect is obvious in the urban area. The inversion of thermal infrared wave segments of summer images shows that the instantaneous surface temperature and the surface temperature of urban and open forestland are relatively high (Fig. 4, C9). Three grades of temperature risk were obtained by the natural discontinuity method (Fig. 4, B5). The high-risk area (39.9\%) was suitable for green space construction to improve the climatic environment of the area. The middle-risk area $(39.7 \%)$ belongs to the transition 

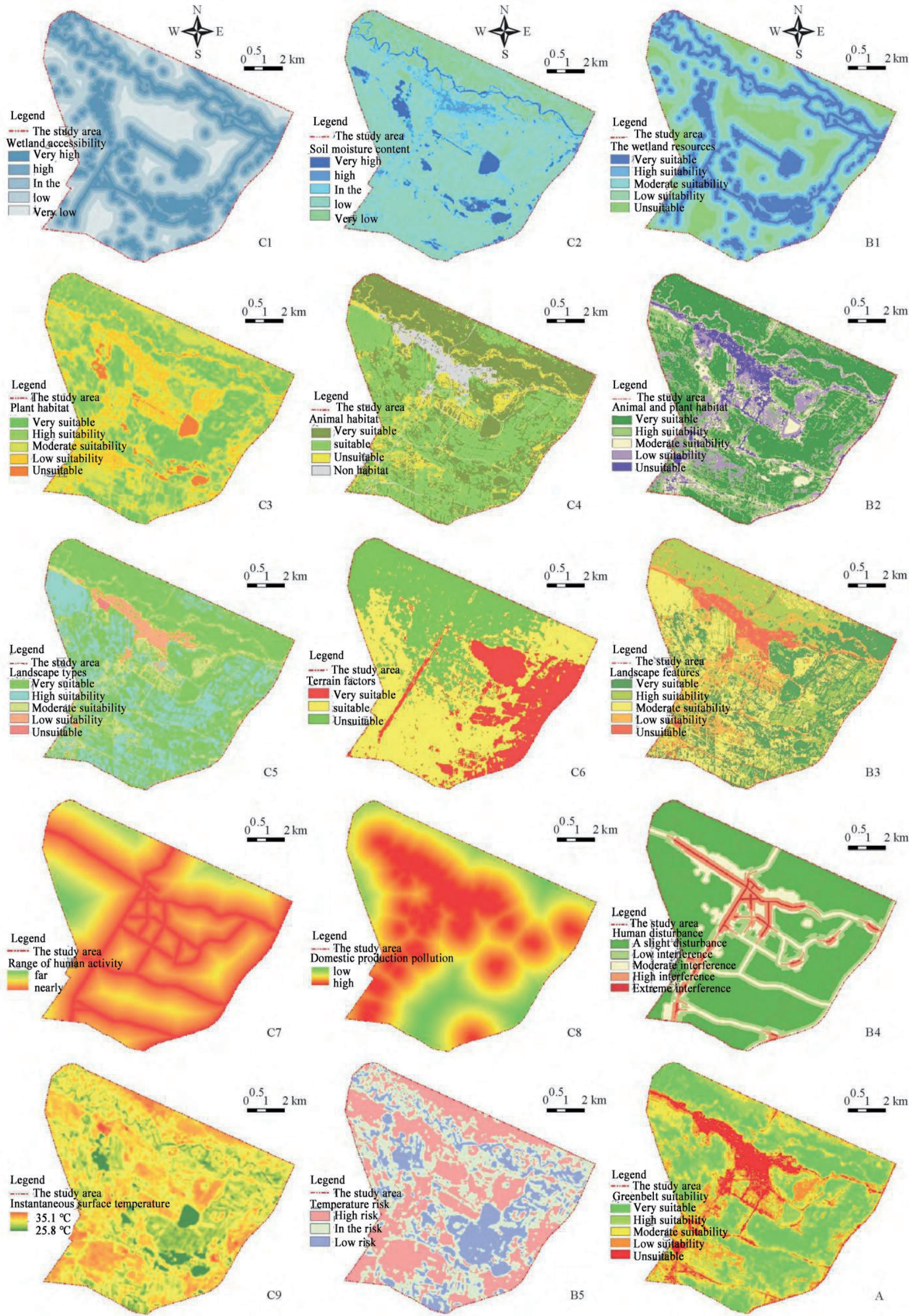

Fig. 4. Superposing Maps of "target-criterion-index" levels's results. 
area. The low-risk area $(20.4 \%)$ is mainly composed of farmland, wetland and dense forest landscapes, which have a high ecological value.

Factor analysis is combined with the five criteria for Beitun agricultural green land suitability (Fig. 4, A); a suitable distribution (23.6\%) of the woods to rich, human recreation and tourism is a relatively frequent area, mainly located to the south of the Eltrix River and around the South Lake area of farmland, including lakes, farmland and opening, without changing the original structure, which is easier for green space ecological infrastructure planning. The high-suitability area $(32.1 \%)$ is distributed around the most suitable area and mainly includes the area at the boundary between the land and the water and the void boundary between agricultural and forest areas and artificial surfaces. It may be affected by human activities to a certain extent, but its own ecological function is strong without drastic interventions, which can guarantee its normal ecological structure and function. Green facilities can be appropriately developed, but attention should be paid to the mode and intensity of human activities, especially the development of recreation routes around Nanhu Lake and Derenshan, which should be coordinated with ecological infrastructure planning. In the mid-suitability area $(21.6 \%)$, the ecological function of the vegetation is low, indirect anthropogenic activities have a strong influence, and the ecosystem structure is poor; this area belongs to the ecological transition zone. The lowsuitability area $(14.5 \%)$ is located in Deren Mountain and includes some bare land with sparse vegetation, which cannot maintain a stable green space growth environment. The unsuitable area $(8.2 \%)$ is the hard surface most directly affected by human activities. The green space in this area has only landscape and shade function, and the generation of other ecological benefits is difficult. The original hard surface reconstruction or the reconstruction of green land requires large investments. To maximize the benefits of urban land and to give full play to the ecological function of green land, it is suggested that the quality of the existing green land be improved, the types of vegetation be enriched and a forest road network be built.

\section{Functional Zoning and Planning Countermeasures of Green Space Ecological Facilities}

The green space suitability evaluation and landscape resource characteristics will be studied.

The forestland, farmland and bare land resources in the district are divided into functional areas to support the planning and construction of green space, to determine the rational utilization and protection of green space resources. At present, landscape resources are divided into four green space ecological function areas: green space ecological restoration areas, green space ecological conservation areas, medium-low impact development areas and green space suitable development areas (Fig. 5).

The ecological restoration area of green space is the area with serious damage to green space ecosystems and a lack of green space resources. Due to the influence of natural condition or the interference of human activities, the green space ecosystem structure is very simple, recovery is not natural, and artificial measures for green space need to be used. This kind of region should set strict management measures, including low impact recovery measures to promote green space ecosystems

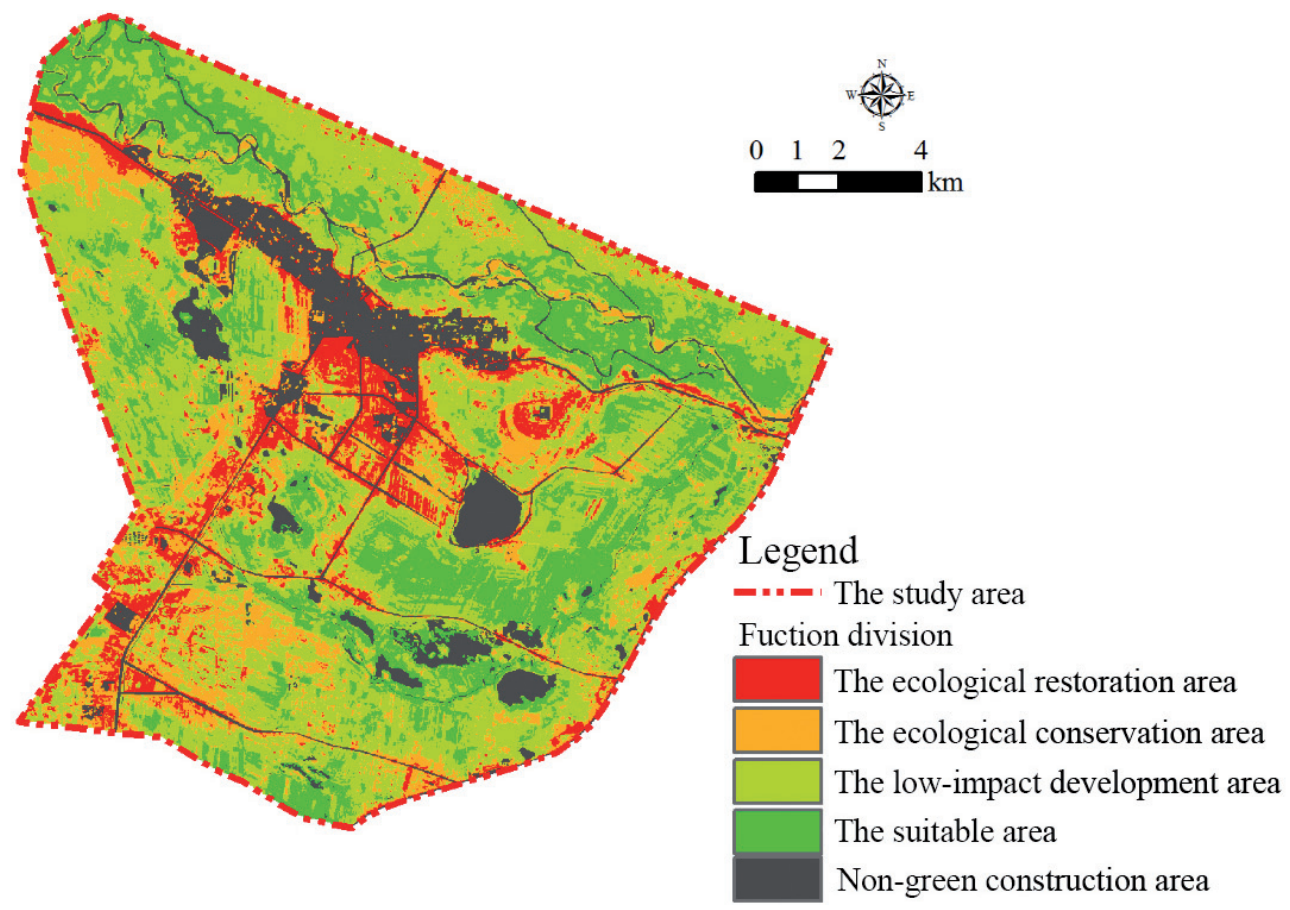

Fig. 5. Zooning map of green space ecological functions. 
or the rapid formation of animal and plant communities. We should strictly protect the natural background, restore native vegetation, improve the diversity and stability of the ecosystem, and establish a benign ecological cycle. If reclamation development is to be carried out, it is necessary to protect the surrounding green space in a planned way and gradually restore the ecological function of regional green space.

The ecological conservation area of green space is an area where the value of animal and plant diversity can be increased by improving the ecological environment. A strict protection scope and management measures can be set to promote the natural restoration of green space ecosystems, and only a certain period of time can be ensured to let the green space in this area achieve self-conservation. If we want to realize the planning and development of green space landscapes as soon as possible, we can promote the construction of green space ecological facilities through artificial measures, realize the benign interaction between ecological protection and economic development through afforestation and other measures, and control human activities.

The quality of the green land landscape in the lowimpact development area is good, and the development and construction of low-impact green land can be carried out to develop ecological tourism, wetland parks and so on. This area has a good location, which is the interface between land and water, and the interface between agriculture, forestry and artificial surfaces. Under the premise of strengthening protections and improving the protection and management system, tourism, leisure sightseeing, fishing, farm entertainment and other activities can be appropriately developed, but with the planning of green space ecological facilities. Human activities have little impact on such a system, but its biodiversity is high, and it has certain green space ecological functions that maintain the natural state and control the construction of buildings.

The suitable area of green space development is far away from the area of human activities, and human activities have little influence on it. However, its biodiversity is high, and the green space landscape is good, which provides a development area for green space planning and regional ecological construction in Beitun city. The green space in this region has the advantages of rich vegetation, excellent natural conditions and a high biological diversity. The maximum benefit can be realized at the minimum cost when developing green space resources or planning green space, and this is an appropriate development area for the later period.

\section{Conclusions}

Drought, salt, alkali, wind and sand are the prominent problems faced by the ecological construction of urban green space in arid areas, and the construction of urban ecological landscapes by introducing a large amount of green vegetation and urban ecological construction fall into the cycle of high energy consumption, high water consumption, biological invasion and so on. Taking Beitun agricultural city in Xinjiang as an example, this study gives full consideration to the natural environmental characteristics of the northwest arid areas, the wetland resources, the wildlife habitat, and the risk and temperature characteristics.

Using remote sensing and alphabet technology, we can quickly and accurately evaluate greenbelt related indexes and spatial and attribute information. Enhance the objectivity of the index factors. A quantifiable and operable evaluation index system for urban green space in arid areas is established. The evaluation results are more intuitive and scientific, and point to the rational distribution of urban green space more efficiently than the traditional system. The research results show that: the system relatively accurately reflect the actual and the demand of the urban green space development in arid areas, for the urban green space system planning and construction to provide scientific theoretical basis, and based on this, advances the functional partition and planning countermeasure of green ecological infrastructure, improve the function of urban green space ecological infrastructure partitions, reasonable use for green land resources distribution, has a certain guiding significance. However, this study also has some limitations. In the future construction practice, it is necessary to add more dimensional evaluation indexes and quantitative measures according to the actual situation, so as to enhance the theoretical guidance and practical operability of the suitability evaluation of urban green space planning research in arid areas.

\section{Conflict of Interest}

The authors declare no conflict of interest.

\section{Acknowledgments}

This study was financially supported by four projects: Xinjiang Production and Construction Corps Think Tank project for Maintaining stability and Guarding border areas, entitled: An empirical study on the construction of standard system of residential environment regulation of Xinjiang Production and Construction Corps and selection of demonstration company(No.21BTZKC06).Social Science Fund of Xinjiang Production and Construction Corps, entitled:Study on the residential form of small towns in the Xinjiang Production and Construction Corps based on the idea of integration of corps and local government(No.18YB08). Shihezi University Science and Technology Achievement Transformation Project, entitled: Study on the Construction of Urban Green Ecological Infrastructure in Xinjiang (No. KX03090215/0205). The National Science and 
Technology Support Program in China, entitled: Research and Demonstration of Eco-town Planning and Local Resource Utilization in Arid Areas (No.2013BAJ03B02).

\section{References}

1. WOLCH J.R., BYRNE J., NEWELL J.P. Urban green space, public health, and environmental justice: The challenge of making cities 'just green enough'. Landscape and Urban Planning, 125, 234, 2014. DOI:10.1016/j. landurbplan.2014.01.017

2. KABISCH N. Ecosystem service implementation and governance challenges in urban green space planning. The case of Berlin, Germany. Land Use Policy, 42, 557, 2015. DOI:10.1016/j.landusepol.2014.09.005

3. HADI N., MOHAMMAD N., HADI S., OLIVIA W. A Systematic Review of Civil and Environmental Infrastructures for Coastal Adaptation to Sea Level Rise. Civil Engineering Journal, 6 (7), 1375, 2020. DOI:10.28991/ cej-2020-03091555

4. LIU H., JIANG W W., LI J. Construction of urban green infrastructure in Cangnan county. Journal of Northwest Forestry University, 30 (5), 237-242, 2014 [In Chinese]. DOI:10.3969/j.issn.1001-7461.2014.05.45.

5. DAVID N., RUDOLF S., GROOT D. Framing Environmental Indicators: Moving From Causal Chains to Causal Networks. Environment, Development and Sustainability, 28 (10), 89, 2008. DOI:10.1007/s10668-0069040-9

6. SANDIPTA D., DASHARATHA P., ANGADI. Assessment of urban sprawl using landscape metrics and Shannon's entropy model approach in town level of Barrackpore sub-divisional region, India. Modeling Earth Systems and Environment, 2020 (prepublish). DOI:10.1007/s40808-020-00990-9

7. FU H., FU G. Land Suitability Evaluation of Urban Green Space Based on GIS in Haikou. Journal of Northwest Forestry University, 31 (4), 291, 2016. [In Chinese]. DOI:10.3969/j.issn.1001-7461.2016.04.49.

8. EMIL T., IRINA R., GALINA D., PLAMEN N., MAGGIE K., CHRISTOS M. Water Stress Mitigation in the Vit River Basin Based on WEAP and MatLab Simulation. Civil Engineering Journal, 6 (11), 2058, 2020. DOI:10.28991/cej2020-03091602

9. CHEN C.N., HU Y., ZHAO M. Progress and prospect of the spatiotemporal change and ecosystem services evaluation of urban green space pattern. Progress in Geography, 39 (10), 1770, 2020 [In Chinese]. DOI:10.18306/ dlkxjz.2020.10.015

10. WANG W., TANG X., ZHOU W X., JING Y. Integrated assessment of ecosystem quality of arid inland river basin based on RS and GIS: A case study on Shiyang River Basin, Northwest China, Chinese Journal of Applied Ecology, 28 (1), 199, 2017 [In Chinese]. DOI: 10.13287/ j.1001-9332.201701.019

11. LI C.L., SHEN S.G., DING L. Evaluation of the winter landscape of the plant community of urban park green spaces based on the scenic beauty esitimation method in Yangzhou, China. PloS one. 15 (10), 2020. DOI:10.1371/ journal.pone. 0239849

12. ZRIBI M., CHAHBI A., SHABOU M., LILI-CHABAANE Z., DUCHEMIN B., BAGHDADI N., AMRI R., CHEHBOUNI A. Soil surface moisture estimation over a semi-arid region using ENVISAT ASAR radar data for soil evaporation evaluation. Hydrology \& Earth System Sciences, 15 (1), 345, 2011. DOI:10.5194/hess-15-345-2011

13. KAMAL A., SHAMSUDDIN S., SOBRI B H., TARMIZI I., NADEEM N., SUPIAH S. Assessment of groundwater potential zones in an arid region based on catastrophe theory. Earth Science Informatics, 8 (3), 539, 2015. DOI:10.1007/s12145-014-0173-3

14. LI Y.Y., SONG Y.Y. Analysis of Green Space Structural Features of Shihezi City in Arid Zone Oasis Based on Landscape. Journal of Northwest Forestry University, 30 (3), 258, 2015 [In Chinese]. DOI:10.3969/j.issn.10017461.2015.03.46.

15. ZHANG S.Y., WU.M. Landscape construction of urban wetland park based on ecological aesthetics research. IOP Conference Series: Earth and Environmental Science, 510 (6), 2020. DOI:10.1088/1755-1315/510/6/062019

16. GUO W., YU L.S., SUN Y.J., CHEN P. Ecological network planning of urban green space in urban center of Shunde district,Foshan city,Guangdong Province of South China[J].Chinese Journal of Ecology, 31 (4), 1022, 2012 [In Chinese]. DOI:10.1007/s11783-011-0280-Z

17. HUANG J.F., WANG R.H., LIN Y., HUANG Q., DONG S., WANG X.F. Analysis of Ecosystem's Dissipation Characteristics of Beitun Oasis, Xinjiang. Journal of Desert Research, 28 (3), 491, 2008 [In Chinese]. DOI:CNKI:SUN:ZGSS.0.2008-03-016

18. LIN Y., WANG R.H., HUANG J.F., XU X.F., LI J. Study on the Succession of Vegetation in Farmlands Discarded from Cultivation in the Beitun Oasis,Xinjiang. Arid Zone Research, 24 (6), 747, 2007 [In Chinese]. DOI:10.1016/ S1872-5791 (07)60026-8

19. HUANG C.B., DIAN Y.Y., ZHOU Z.X., WANG D., CHEN R.D. Forest change detection based on time series images with statistical properties. Journal of Remote Sensing, 19 (4), 657, 2015 [In Chinese]. DOI:10.11834/jrs.20154104.

20. CHEN S. Construction and Application of Suitability Evaluation Index System for Urban Park Green Space. Journal of Northeast Forestry University, 39 (7), 105, 2011 [In Chinese]. DOI:10.3969/j.issn.1000-5382.2011.07.032.

21. HE D., JIN F J., ZHOU J. Urban construction land suitability evaluation in resource - based cities: Taking the grand canal ecologic and economic area as an example. Geographical Research, 30 (4), 655, 2011 [In Chinese]. DOI:10.3724/SP.J.1011.2011.00415

22. SHEN S.G., FAN C.J., WANG H., XU X.Z. Protection and Development of the Scenic Spots in Heihushan Based on Land Ecological Suitability Evaluation. Journal of Northwest Forestry University, 28 (2), 202, 2013 [In Chinese]. DOI:10.3969/j.issn.1001-7461.2013.02.40.

23. MALMIR M., ZARKESH M.M.K., MONAVARI S.M., JOZI S.A., SHARIFI E. Analysis of land suitability for urban development in Ahwaz County in southwestern Iran using fuzzy logic and analytic network process (ANP). Environmental Monitoring \& Assessment, 188 (8), 447, 2016. DOI:10.1007/s10661-016-5401-5

24. ZHANG C.Q., DONG B., LIU L.P., PENG W.J., CHEN L.N., ZHOU Q., WANG Q., LI J.L., WANG C., HUANG H., WU J., LI X. Study on ecological risk assessment for land-use of wetland based on different scale. Joumal of the Indian Society of Remote Sensing, 44 (5), 821, 2016. DOI:10.1007/s12524-015-0518-5

25. GAO B.C. NDWI - a normalized difference water index for remote sensing of vegetation liquid water from space. Remote Sensing of Environment, 58 (3), 257, 1996. DOI:10.1016/S0034-4257 (96)00067-3 
26. PENG J., MA J., DU Y.Y., ZHANG L.Q., HU X.X. Ecological suitability evaluation for mountainous area development based on conceptual model of landscape structure, function, and dynamics. Ecological Indicators, 61, 500, 2016. DOI:10.1016/j.ecolind.2015.10.002

27. LI Q.S., HUANG J.L., WANG C., LIN H.S. Land Development Suitability Evaluation of Pingtan Island Based on Scenario Analysis and Landscape Ecological Quality Evaluation. Sustainability, 9 (7), 15, 2017. DOI:10.3390/su9071292

28. JIMÉNEZ-MUÑOZ J.C., SOBRINO J.A., SKOKOVIĆ D., MATTAR C., CRISTOBAL J. Land Surface Temperature
Retrieval Methods From Landsat-8 Thermal Infrared Sensor Data. IEEE Geoscience \& Remote Sensing Letters, 11 (10), 1840, 2014. DOI:10.1109/LGRS.2014.2312032

29. KLINE J.D., MOSES A., ALIG R.J. Integrating urbanization into landscape-level ecological assessments. Ecosystems, 1, 3, 2001. DOI:10.1007/s100210000056

30. FERRETTI V., POMARICO S. Ecological land suitability analysis through spatial indicators: An application of the Analytic Network Process technique and Ordered Weighted Average approach. Ecological Indicators, 34 (11), 507, 2013. DOI:10.1016/j.ecolind.2013.06.005 
